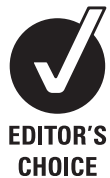

CHOICE

\title{
Paediatric hanging associated out of hospital cardiac arrest in Melbourne, Australia: characteristics and outcomes
}

\author{
C Deasy, ${ }^{1,2,3} \mathrm{~J} \mathrm{Bray}^{1}{ }^{1} \mathrm{~K}$ Smith, ${ }^{1,2}$ L R Harriss, ${ }^{1,2}$ S A Bernard, ${ }^{1,2,3}$ P Cameron, ${ }^{2,3}$ \\ On behalf of the Victoria Ambulance Cardiac Arrest Registry steering committee
}

\begin{abstract}
See Commentary, p 371
${ }^{1}$ Ambulance Victoria, Victoria, Australia

${ }^{2}$ Department of Epidemiology and Preventive Medicine,

Monash University, Melbourne, Australia

${ }^{3}$ The Alfred Hospital,

Melbourne, Victoria
\end{abstract}

\section{Correspondence to}

Dr C Deasy, Monash University, Department of Epidemiology and Preventive Medicine, Alfred Hospital, Level 3 Burnet Building, 89 Commercial Road Melbourne 3004, Australia; conordeasy@hotmail.com

Accepted 4 January 2011 Published Online First 18 February 2011

\begin{abstract}
Introduction Hanging is a rare but devastating cause of out of hospital cardiac arrest (OHCA). The characteristics and outcomes of hanging associated OHCA in the paediatric age group are described.

Methods The Victorian Ambulance Cardiac Arrest Registry was searched for patients aged less than 18 years where the precipitant cause of OHCA was hanging. Results were cross checked with the coronial database.
\end{abstract}

Results During the years 2000-2009, there were 680 paediatric cardiac arrests of which $53(7.8 \%)$ were precipitated by hanging with an incidence of 4.4 per million paediatric patients $(<18$ years) per year. Median age was 16 (IOR 14-17) years and 58.5\% were males. Five were unintentional hangings; median age 3 (IOR 2-4) years. The youngest deliberate hanging associated OHCA was aged 10 years. Most hangings occurred in a house (85\%) and bystander cardiopulmonary resuscitation (CPR) was performed in $30 \%$. Asystole was the most common initial cardiac arrest rhythm seen in 50 cases (94\%) while three patients had pulseless electrical activity. The emergency medical services (EMS) attempted resuscitation in 18 patients $(34 \%)$, inserting an endotracheal tube in 13 patients. The majority $(n=41)$ were not transported; seven patients were transported with return of spontaneous circulation (ROSC) and five patients were transported with ongoing CPR. Victims who had bystander CPR were more likely to have EMS attempted resuscitation $(p<0.001)$. Only patients who had received bystander CPR achieved ROSC $(p<0.001)$. Three patients survived to hospital discharge; two survivors suffered severe neurological injury (Cerebral Performance Category Scale 3-4). Conclusion Non-intentional hanging is rare but deliberate hanging with suicidal intent represents a significant proportion of OHCAs in patients under 18 years of age. A focus on prevention is key, as outcomes are poor, with survivors likely to suffer a severe neurological insult.

\section{INTRODUCTION}

Hanging is a rare but devastating cause of out of hospital cardiac arrest (OHCA) in all age groups, including paediatrics. ${ }^{1}{ }^{2}$ While the estimated lethality for hanging is $83 \%,{ }^{3}$ Penney et al ${ }^{4}$ found a Glasgow Coma Scale score of 3 and cardiac arrest at the scene were associated with 100\% mortality rate even when resuscitation restored a spontaneous circulation (ROSC) prior to hospital admission.

Both accidental hanging and deliberate hanging are seen in the paediatric age group. Certain
Australian states have enacted legislation providing uniform guidelines for managing curtain cords and cleats to address causes of accidental hanging. ${ }^{5}$ Hanging as a method of suicide has increased over the past two decades and is now the most frequent method of suicide in Australia ${ }^{6}$ in all age groups.

Much of the published work on hanging in the paediatric age group has taken the form of case reports rather than large case series. ${ }^{7}$ The aim of this study is to describe the characteristics and outcomes of paediatric patients ( $<18$ years of age) suffering OHCA caused by hanging.

\section{METHODS}

The study setting was Melbourne, Australia, which has a population of 3.9 million, of whom 840400 are under 18 years of age. The emergency medical service (EMS) comprises ambulance paramedics who have some advanced life support skills (laryngeal mask airway, intravenous epinephrine) and mobile intensive care ambulance paramedics who are authorised to perform endotracheal intubation and administer a wider range of cardiac drugs. Mobile intensive care ambulance paramedics are dispatched to patients with critical illness, including patients with cardiac arrest. In addition, fire fighters are dispatched to patients with suspected cardiac arrest in the inner third of the Melbourne urban area. ${ }^{8}$ The prehospital cardiac arrest protocols follow the recommendations of the Australian Resuscitation Council. ${ }^{9} 10$

Since December 2007, all patients attended by paramedics have patient care data collected in an electronic patient record. Previous years involved a paper patient care record. Selected data from patient care records is collected from patients in cardiac arrest and stored on the Victorian Ambulance Cardiac Arrest Registry (VACAR). The VACAR also includes some data from the hospital record for those patients transferred to hospital, including outcome. The aetiology of the arrest is classified into 13 different diagnostic categories, one of which is hanging (figure 1); these are based on clinical assessments and bystander information recorded by paramedics in the patient care record. Patients were included if they were aged $<18$ years and in OHCA on arrival of the EMS, where the presumed cause was hanging, during the time period January 2000 to December 2009

The Paediatric Cerebral Performance Category Scale (PCPC) $)^{10}$ was used to summarise the level of neurological function. A score of 1 is achieved if the 
Figure 1 Precipitant cause of 680 cases of paediatric out of hospital cardiac arrest (0-18 years) in Melbourne, Australia (2000-2009). SIDS, sudden infant death syndrome.

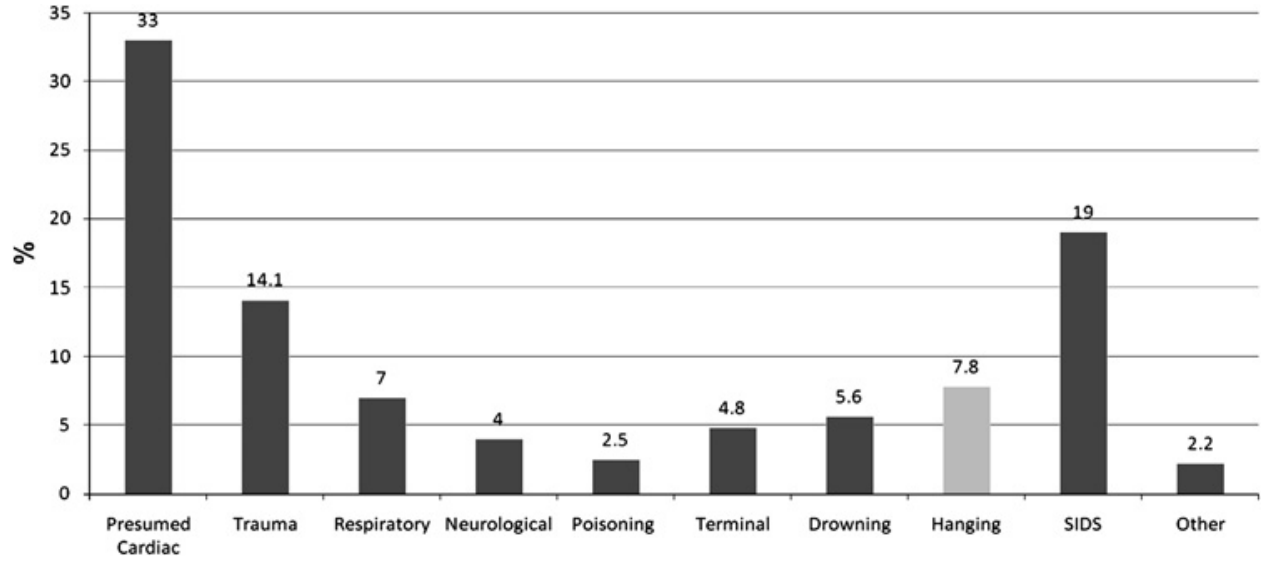

subject is normal at an age appropriate level. PCPC 2 is mild disability; the subject is conscious, alert and able to interact at age appropriate level; a school aged child attending regular school classroom but grade perhaps not appropriate for age; here there may be a mild neurological deficit. PCPC 3 is moderate disability; the subject is conscious, has sufficient cerebral function for age appropriate independent activities of daily life; school aged child attending special education classroom and/or learning deficit present. PCPC 4 represents severe disability; the patient is conscious but dependent on others for daily support because of impaired brain function. PCPC 5 is coma or vegetative state; any degree of coma without the presence of all brain death criteria; unawareness, even if awake in appearance, without interaction with environment; cerebral unresponsiveness and no evidence of cortex function (not aroused by verbal stimuli); possibility of some reflexive response, spontaneous eye opening and sleep-wake cycles. PCPC 6 is brain death; apnoea, areflexia and/or electroencephalographic silence. We ascertained the PCPC score at hospital discharge by retrospective chart review.

The National Coroners Information System was accessed for cases identified by VACAR to ensure all hanging deaths in Melbourne were identified and included in the study and to verify cause of death and ascertain injuries identified at post mortem.

The collection of cardiac arrest data by VACAR was approved by the ethics committees of Melbourne hospitals receiving Research Committee of Ambulance Victoria, the Department of Justice Research Committee and Monash University Human Research Ethics Committee.

\section{Statistical analysis}

All data were entered into an Access software cardiac arrest registry database (V.2003, Microsoft, Redmond, Washington, USA). Statistical calculations were performed on STATA software (V.10.0 Stata Corporation). $\chi^{2}$ analyses were used for categorical variables. Continuous variables were compared using the t test (normal distribution) or Mann-Whitney or KruskalWallis test (skewed distribution).

\section{RESULTS}

In the time period from 2000 to 2009 , there were 680 OHCAs in children aged $<18$ years. Hanging was the fourth commonest precipitant cause of OHCA and occurred in 53 (7.8\%) cases (figure 1). The incidence of hanging precipitated OHCA in the $0-18$ year old age group was 4.4 per million per year. Only five (9.4\%) hangings were accidental.

The Utstein characteristics and outcomes of patients with OHCA due to hanging are described in table 1.

Median (IOR) age of the victims was $16(14-17)$ years and most were male (58.5\%). Compared with all causes of paediatric OHCA, those related to hanging were significantly older cardiac arrests by ambulance. The study was approved by the

Table 1 Characteristics and outcomes of 680 cases of paediatric out of hospital cardiac arrest (0-18 years) associated with hanging in Melbourne, Australia (2000-2009)

\begin{tabular}{|c|c|c|c|c|}
\hline Characteristic & Patients with ROSC & Survivors & Non-survivors & Overall \\
\hline No (\%) & 7 (13.2) & $\begin{array}{l}3(5.6), 1(1.8) \\
\text { neurologically intact }\end{array}$ & $50(94.3)$ & 53 \\
\hline Age (years) (median (IQR)) & $10(3-14)$ & $14(10-16)$ & $16(14-17)$ & $16(14-17)$ \\
\hline Males (\%) & 57 & 66.6 & 58 & 58.5 \\
\hline Bystander witnessed (n (\%)) & $7(100)$ & $3(100)$ & $3(6)$ & $3(5.6)$ \\
\hline Bystander CPR (n (\%)) & $7(100)$ & $2(66.6)$ & $18(36)$ & $20(37.7)$ \\
\hline \multicolumn{5}{|l|}{ Initial rhythm (n (\%)) } \\
\hline VF/VT & 0 & 0 & 0 & 0 \\
\hline Asystole & $6(85)$ & $2(66.6)$ & $48(96)$ & $50(94.3)$ \\
\hline PEA & $1(14.3)$ & $1(33.3)$ & $2(4)$ & $3(5.6)$ \\
\hline \multicolumn{5}{|l|}{ Location (n (\%)) } \\
\hline Home & $7(100)$ & $3(100)$ & $42(84)$ & $45(85)$ \\
\hline Public place & 0 & 0 & $8(16)$ & $8(15)$ \\
\hline $\begin{array}{l}\text { EMS response time (min) } \\
\text { (median (IOR)) }\end{array}$ & $6.9(6-10)$ & $6.9(6.6-7)$ & $\begin{array}{l}7.8(6-10.5) \\
p=0.67\end{array}$ & $7(6-10)$ \\
\hline
\end{tabular}

CPR, cardiopulmonary resuscitation; EMS, emergency medical services; PEA, pulseless electrical activity; ROSC, return of spontaneous circulation; VF, ventricular fibrillation; VT, ventricular tachycardia. 

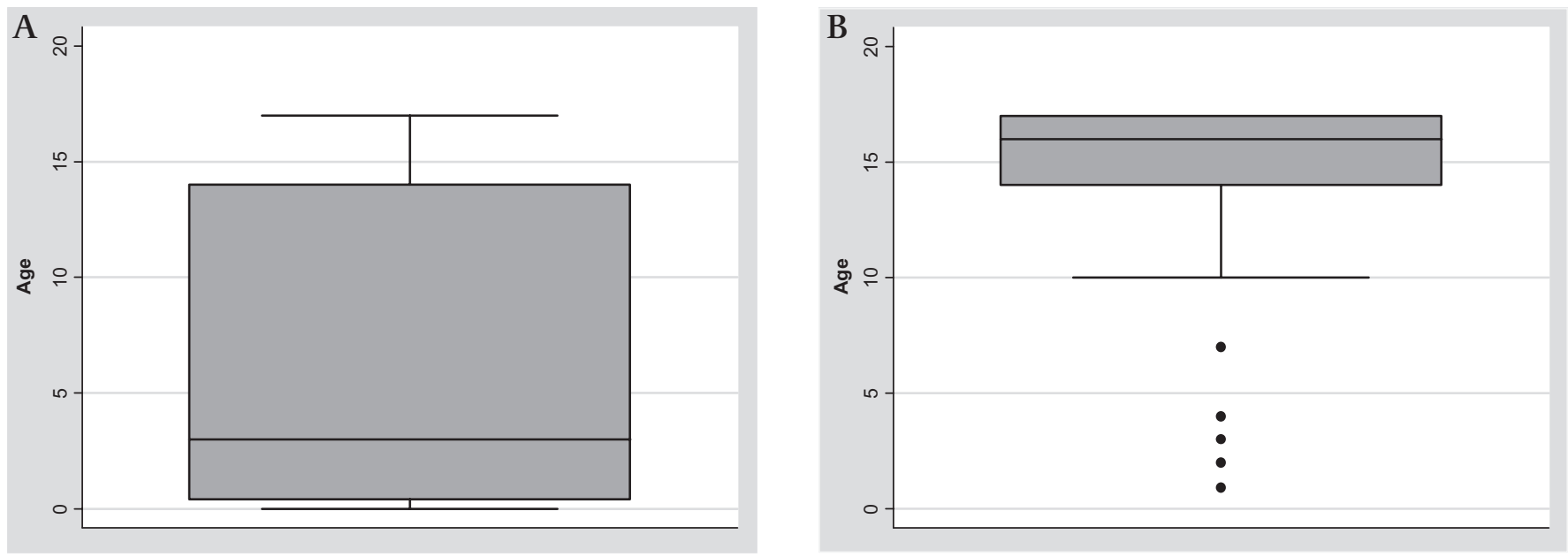

Figure 2 Comparison of age between $(A)$ out of hospital cardiac arrest $(\mathrm{OHCA})<18$ years and $(\mathrm{B}) \mathrm{OHCA}<18$ years where hanging was the precipitant cause.

(median 16 years vs 3 years; $\mathrm{p}<0.001$ ) (figure 2). Accidental hangings were younger (median age 3 , IOR 2-4 years) than deliberate hangings (median age 16, IOR 15-17 years). The youngest deliberate hanging OHCA was aged 10 years.

Most hangings occurred in the home (85\%) (table 1) and the most common time of EMS activation for a paediatric hanging OHCA was 16:00 (range 11:00-23:00). Two cases were part of a suicide pact; both bodies were found together.

The most common initial rhythm was asystole ( $n=50,94 \%)$; pulseless electrical activity (PEA) was seen in the remaining three cases. None of the patients had a shockable rhythm on initial assessment. EMS attempted resuscitation in 18 cases $(33 \%)$; 41 cases $(77.3 \%)$ were declared dead at the scene, five $(9.4 \%)$ were transported with ongoing resuscitation and seven $(13 \%)$ were transported to hospital after achieving ROSC. Bystander cardiopulmonary resuscitation (CPR) was performed in $37.7 \%$ and in all cases that were transported with ROSC. Victims who had bystander CPR were more likely to have EMS attempted resuscitation $(\mathrm{p}<0.001)$ and only patients who received bystander CPR achieved ROSC in advance of hospital arrival $(\mathrm{p}<0.001)$.

Only three $(5.6 \%)$ patients survived to leave hospital: two asystolic arrests and one PEA. Of the three survivors, one was discharged neurologically intact (PCPC score 1) and the other two survivors suffered significant neurological injury with PCPC scores of 3 and 4 , respectively.

The autopsy was available in $80 \%$ of cases. Hyoid bone fractures were described in two cases. There were no cases of cervical spine fracture or major vessel tears seen at autopsy.

\section{DISCUSSION}

This is the largest case series to date describing hanging precipitated OHCA in the paediatric and adolescent age group. Hanging associated OHCA was relatively rare, with an incidence of 4.4 per million per year in the $0-18$ year old age group. In this study, the outcomes were poor; there were few survivors, with most suffering severe neurological insult.

The mechanism of death in deliberate and accidental hanging is debated but it is most likely due to vascular obstruction of neck vessels and cerebral hypoxia. Airway injuries severe enough to interfere with airway management are uncommon, ${ }^{11} 12$ and although airway disruption has been described, airway closure is not thought to be a significant factor ${ }^{12} 13$ as death from hanging has been described in tracheotomised patients. ${ }^{14} 15$ In this case series, there were two cases of incidental hyoid bone fractures found at autopsy; there was no case of airway disruption.

Cervical spine fracture is a function of age, suspension time and drop height. ${ }^{16}$ The classic 'Hangman's fracture' through the neural arch of the second cervical vertebra producing death by spinal cord injury is rarely described in suicidal hanging as the body does not usually fall from a great height. ${ }^{14} 1718$ Adams, ${ }^{19}$ in reviewing the literature, found an incidence of spinal injuries associated with hanging of $0.6 \%$ in an adult population. Children may sustain spinal cord injury without bony spine abnormality (SCIWORA) ${ }^{20} 21$ making interpretation of the absence of cervical spine fractures at autopsy in this case series open to debate.

There were five accidental hangings in this case series, two involving curtain cords. The Australian government published a blind and curtain cords safety alert brochure ${ }^{5}$ in 2007 . The brochure advises parents and child carers to keep cots and furniture that can be climbed on away from windows that have curtain or blind cords, to use cleats and cord wind-ups, to keep cords at least $1.6 \mathrm{~m}$ above the floor, to cut loops and to keep cords that must be looped under tension with tie-down devices. Certain Australian states have enacted legislation providing uniform guidelines for managing curtain cords and cleats that includes warning labels and written safety information for parents in an attempt to address this cause of accidental hanging.

While there has been a decline in suicide in Australia, hanging has increased and is now the most common method of completed suicide ${ }^{6}$ in all age groups. Large et $a l^{6}$ reported an increased incidence of male hanging, 5.65 per 100000 males for the period 1988-1997 increasing to 7.38 per 100000 males for the period 1998-2007 in Victoria while the overall suicide rate dropped from 19.3 to 16.2 per 100000 over the two decades. This has been influenced by Australia's national suicide prevention strategy ${ }^{22}$ and measures to reduce the availability of some lethal methods of committing suicide, including the firearms 'buy back' scheme, ${ }^{23} 24$ the introduction of catalytic converters in all new cars, ${ }^{25}$ changes in the pattern of prescription of antidepressant medications away from tricyclic antidepressants and an increase in the use of the less toxic serotonin reuptake inhibitors. ${ }^{26}$

The Resuscitation Outcomes Consortium Epistry Cardiac Arrest, a North American network of 11 geographic sites 
investigating $\mathrm{OHCA},{ }^{2}$ report $5 \%$ of paediatric OHCA being due to hanging in the age group $<20$ years old. While our data are from an urban metropolitan single EMS service setting, the Resuscitation Outcomes Consortium Epistry Cardiac Arrest includes over 260 EMS agencies, rural and urban, centralised and decentralised, municipal and private. It may be that their lower rate of hanging OHCA is due to greater availability of firearms.

The most likely successful intervention to improve outcomes from paediatric OHCA (especially hanging) is preventing the event occurring in the first instance. Whether the paediatric OHCA preventive link in the chain of survival might be affected by a 'means reduction' approach ${ }^{20}$ is debatable. Applying means reduction to hanging where the materials used include everyday household items, such as curtain cords, bed sheets, belts, ropes or dog leashes, is difficult. Creating a safer environment includes eliminating or minimising hanging points and restricting access to items that could be used in a hanging. ${ }^{27} 28$ Focussing attention on educating children about the dangers of playing with ligatures is a double edged sword, an unintended consequence could be increased interest and curiosity in hanging. ${ }^{7}$ In this study, the five accidental hangings would not necessarily have been reduced by such an approach but parental awareness and supervision may have prevented some.

The majority of cases in this case series were suicidal acts. Large et al suggest that suicide in Australia might be reduced by three broad types of public health measures. ${ }^{6}$ Firstly, based on evidence that the early treatment of psychotic illness can reduce suicide attempts, ${ }^{29}$ they suggest provision of mental health services to a greater proportion of previously untreated mentally ill people. Secondly, they suggest greater efforts in identifying and treating high risk individuals but acknowledging the potential is limited by the modest sensitivity and specificity of methods used for assessing suicide risk. ${ }^{30} 31$ And thirdly, and their favoured, is to further limit the availability of lethal means. ${ }^{6}$ Our study suggests that reducing lethal means is limited by the widespread availability of means of hanging. Educating parents and children to take seriously those who threaten to self harm may, like in the case of accidental hanging, be a double edged sword, an unintended consequence being increased awareness and interest in hanging as a method of self harm and suicide.

Hanging associated OHCA in children represents one of the most stressful and distressing scenarios EMS providers deal with. Here, the psychological stress associated with dealing with not only the pulseless victim but the victim's hysterical parent or family should not be underestimated. Ensuring adequate emotional support to the EMS providers involved is challenging in the immediate aftermath. Scenario and simulation based education featuring hanging OHCA may be helpful in opening discussion and pre-empting some of the problems that may be encountered in real life by EMS providers.

\section{LIMITATIONS}

It is acknowledged that some children who undergo CPR in the out of hospital arena are likely to never have been pulseless. ${ }^{32}$ Accurate assessment of peripheral pulses and recognition of pulselessness has been shown to be unreliable for children. ${ }^{33}$ Patients in our study had an ECG recording determining their cardiac arrest rhythm. The median age of hanging paediatric cardiac arrest is 16 years and palpation of a pulse is more reliable in older children and therefore the likelihood of mistaking sinus rhythm for a PEA OHCA is unlikely. Autopsy reports were available in $80 \%$ of cases and revealed two cases of incidental hyoid bone fracture. Given the possibility of SCIWORA, the absence of cervical fracture on autopsy is of questionable significance.

\section{CONCLUSION}

Non-intentional hanging is rare but deliberate hanging with suicidal intent represents a significant proportion of OHCAs in patients under 18 years of age. A focus on prevention is key, as the outcomes from paediatric OHCA associated with hanging are poor, with survivors likely to suffer a severe neurological insult

Funding $\mathrm{CD}$ is in receipt of an Overseas PhD Student Scholarship from Monash University. Ambulance Victoria and the Coroner's Office provided support.

\section{Competing interests None.}

Ethics approval The study was approved by the Research Committee of Ambulance Victoria, the Department of Justice Research Committee and Monash University Human Research Ethics Committee.

Contributors All authors made substantial contributions to all of the following: (1) the conception and design of the study, or acquisition of data, or analysis and interpretation of the data, (2) drafting the article or revising it critically for important intellectual content and (3) final approval of the version to be submitted.

Provenance and peer review Not commissioned; externally peer reviewed.

\section{REFERENCES}

1. Deasy C, Bernard SA, Cameron $P$, et al. Epidemiology of paediatric out-of-hospital cardiac arrest in Melbourne, Australia. Resuscitation 2010;81:1095-100.

2. Atkins DL, Everson-Stewart S, Sears GK, et al. Epidemiology and outcomes from out-of-hospital cardiac arrest in children: the Resuscitation Outcomes Consortium Epistry-Cardiac Arrest. Circulation 2009;119:1484-91.

3. Elnour AA, Harrison J. Lethality of suicide methods. Inj Prev 2008;14:39-45.

4. Penney DJ, Stewart AH, Parr MJ. Prognostic outcome indicators following hanging injuries. Resuscitation 2002;54:27-9.

5. Australian Competition and Consumer Commission. Blind and curtain cords, safety alert. Australian Competition and Consumer Commission, 2007.

6. Large MM, Nielssen OB. Suicide in Australia: meta-analysis of rates and methods of suicide between 1988 and 2007. Med J Aust 2010 192:432-7.

7. Wyatt JP, Wyatt PW, Squires TJ, et al. Hanging deaths in children. Am J Forensic Med Pathol 1998;19:343-6.

8. Smith KL, Peeters A, McNeil JJ. Results from the first 12 months of a fire firstresponder program in Australia. Resuscitation 2001;49:143-50.

9. Australian Resuscitation Council. Guidelines. http://www.resus.org.au (accessed Jun 2010).

10. Ambulance Victoria. Clinical practice guidelines. http://www.ambulance.vic.gov. au/Paramedics/Qualified-Paramedic-Training/Clinical-Practice-Guidelines.html (accessed Jun 2010).

11. Kaki A, Crosby ET, Lui AC. Airway and respiratory management following non-letha hanging. Can J Anaesth 1997:44:445-50.

12. Deshpande $\mathbf{S}$. Laryngotracheal separation after attempted hanging. $\mathrm{Br} \mathrm{J}$ Anaesth 1998;81:612-14

13. Raja U, Sivaloganathan S. Decapitation - a rare complication in hanging. Med Sci Law 1997;37:81-3

14. Iserson KV. Strangulation: a review of ligature, manual, and postural neck compression injuries. Ann Emerg Med 1984;13:179-85.

15. McHugh TP, Stout M. Near-hanging injury. Ann Emerg Med 1983;12:774-6

16. Morild I. Fractures of neck structures in suicidal hanging. Med Sci Law 1996;36:80-4

17. Bradshaw DA, Amundson DE. Complications of suicidal hanging: a case report and brief review. Mil Med 1994;159:720-1.

18. Aufderheide TP, Aprahamian C, Mateer JR, et al. Emergency airway management in hanging victims. Ann Emerg Med 1994;24:879-84.

19. Adams. Near hanging. Emerg Med 1999;11:17-21.

20. Pang D, Wilberger JE Jr. Spinal cord injury without radiographic abnormalities in children. J Neurosurg 1982;57:114-29

21. Kriss VM, Kriss TC. SCIWORA (spinal cord injury without radiographic abnormality) in infants and children. Clin Pediatr (Phila) 1996;35:119-24.

22. Taylor SJ, Kingdom D, Jenkins R. How are nations trying to prevent suicide? An analysis of national suicide prevention strategies. Acta Psychiatr Scand 1997:95:457-63

23. Klieve H, Barnes M, De Leo D. Controlling firearms use in Australia: has the 1996 gun law reform produced the decrease in rates of suicide with this method? Soc Psychiatry Psychiatr Epidemiol 2009:44:285-92.

24. Chapman S, Alpers P, Agho K, et al. Australia's 1996 gun law reforms: faster falls in firearm deaths, firearm suicides, and a decade without mass shootings. Inj Prev 2006;12:365-72.

25. Brennan C, Routley V, Ozanne-Smith J. Motor vehicle exhaust gas suicide in Victoria, Australia 1998-2002. Crisis 2006;27:119-24. 
26. Hall WD. How have the SSRI antidepressants affected suicide risk? Lancet 2006;367:1959-62.

27. Department of Mental Health and Substance Abuse World Health Organization, International Association for Suicide Prevention. Preventing suicide in jails and prisons. Geneva: World Health Organization, 2007.

28. US Department of Health and Human Services. National Strategy for Suicide Prevention: Goals and Objectives for Action. Rockville: US Public Health Service, 2001.

29. Melle I, Johannesen JO, Friis S, et al. Early detection of the first episode of schizophrenia and suicidal behavior. Am J Psychiatry 2006:163:800-4.
30. Pokorny AD. Suicide prediction revisited. Suicide Life Threat Behav 1993;23:1-10

31. Motto JA, Bostrom A. Empirical indicators of near-term suicide risk. Crisis 1990:11:52-9.

32. Donoghue AJ, Nadkarni V, Berg RA, et al. Out-of-hospital pediatric cardiac arrest: an epidemiologic review and assessment of current knowledge. Ann Emerg Med 2005:46:512-22.

33. Tibballs $\mathbf{J}$, Russell P. Reliability of pulse palpation by healthcare personnel to diagnose paediatric cardiac arrest. Resuscitation 2009;80:61-4.

\section{Information comes First at BMJ Journals Online}

Online First is an exciting innovation that allows you to see selected articles in their raw manuscript form a few days after acceptance. Through Online First you'll be able to access articles that have been peer reviewed and accepted for publication before anyone else!
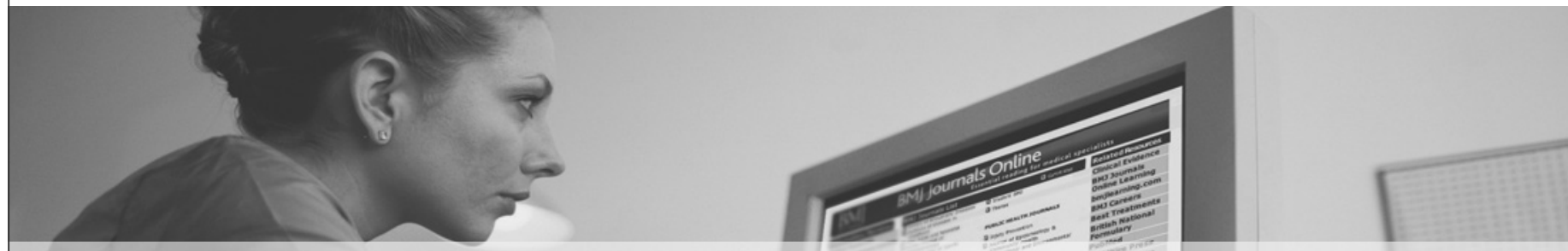

New articles are added every week so make sure that you regularly check the website for updates. To view articles Online First, simply click on the Online First icon at any of these websites:

ard.bmj.com adc.bmj.com bjo.bmj.com bjsm.bmj.com gut.bmj.com heart.bmj.com jcp.bmj.com jech.bmj.com jmg.bmj.com jnnp.bmj.com oem.bmj.com sti.bmj.com thorax.bmj.com 